DOI: https://doi.org/10.46667/renbio.v13i1.265

\title{
Auxiliando dificuldades de aprendizagem apontadas por alunos do ensino médio por meio de objetos virtuais de aprendizagem
}

\author{
Assisting learning disabilities pointed out by high school students \\ through virtual learning objects
}

Pamela Beatriz Menezes Lemos ${ }^{1}$

\begin{abstract}
Resumo
O Estágio é um processo que capacita o futuro professor, dentre outras habilidades, para a utilização de tecnologias associadas à Educação como os Objetos Virtuais de Aprendizagem (OVA). No estágio supervisionado realizado pela autora desenvolveu-se um OVA site, centrado nas dificuldades em Genética, Evolução e Ecologia apontadas por alunos do $3^{\circ}$ ano do E.M. de uma escola pública periférica, com o objetivo de auxiliar suas dúvidas e promover o acesso a diferentes tipos de metodologias e abordagens de ensino-aprendizagem em um contexto de vulnerabilidade social e econômica. O percurso metodológico consistiu: na reunião das maiores dificuldades para nortear a construção do site; elaboração do conteúdo a ser mediado através do site; desenvolvimento da estrutura em hipertexto por meio de ferramentas e programas computacionais; três horas/aulas para aplicação de explicações teóricas, exemplos, imagens e um simulador; e avaliação. Inferiu-se que a utilização de OVA's, quando preocupada e orientada pelas necessidades dos alunos, desencadeia maior interesse refletido na maior participação, gerando melhor aprendizado dos conteúdos. Também foi notável o desenvolvimento de habilidades cognitivas extremamente necessárias para se viver em um mundo digitalizado como o momento atual além de desenvolver competências fundamentais para a cidadania.
\end{abstract}

Palavras-chave: Objeto Virtual de Aprendizagem; Ensino Médio; Genética.

\begin{abstract}
The Internship is a process that enables the future teacher, among other skills, to use technologies associated with Education such as Virtual Learning Objects (VLOs). In the supervised internship carried out by the author, an OVA site was developed, focused on the difficulties in Genetics, Evolution and Ecology pointed out by 3rd year students from a peripheral public school, with the objective of helping their doubts and promoting the access to different types of teaching-learning methodologies and approaches in a context of social and economic vulnerability. The methodological path consisted of: the meeting of the greatest difficulties to guide the construction of the site; elaboration of the content to be mediated through the site; development of the hypertext structure by means of tools and computer programs; three hours/classes to apply theoretical explanations, examples, images and a simulator; and evaluation. It was inferred that the use of OVA's, when concerned and guided by the needs of students, triggers greater interest reflected in greater participation, generating better learning of content. It was also remarkable the development of cognitive skills extremely necessary to live in a digitalized world as the current moment, in addition to developing fundamental skills for citizenship.
\end{abstract}

Keywords: Virtual Learning Object; High School; Genetics.

\footnotetext{
${ }^{1}$ Especialização em Gestão Ambiental Diagnóstico e Adequação - Instituto Federal do Triângulo Mineiro (IFTM). Uberaba, MG - Brasil. Graduação em Ciências Biológicas. Universidade Federal do Triângulo Mineiro (UFTM) - Uberaba, MG - Brasil. E-mail: pamelalemosbio@ outlook.com.br

Submetido em: 25/10/2019 - Aceito em: 01/03/2020
}

REnBio - Revista de Ensino de Biologia da SBEnBio - ISSN: 1982-1867 - vol. 13, n. 1, p. 3-21, 2020 


\section{0 ensino de genética, evolução e ecologia no ensino médio}

Os conteúdos curriculares do Ensino Fundamental e Médio no Brasil são orientados pelos Parâmetros Curriculares Nacionais (1997), dando suporte para as mediações que serão realizadas quanto ao conteúdo disciplinar assim como também para que os conteúdos relacionados à formação cidadã sejam efetivados. Observando-se os PCN's para o Ensino Médio (2000), percebe-se a importância da indissociabilidade do conteúdo curricular de Biologia para representação fiel da realidade vivenciada pelos alunos, pois são seres vivos e, como tais, estabelecem relações com o meio e outros seres:

O aprendizado disciplinar em Biologia, cujo cenário, a biosfera, é um todo
articulado, é inseparável das demais ciências. A própria compreensão do surgimento
e da evolução da vida nas suas diversas formas de manifestação demanda uma
compreensão das condições geológicas e ambientais reinantes no planeta primitivo.
O entendimento dos ecossistemas atuais implica um conhecimento da intervenção
humana, de caráter social e econômico, assim como dos ciclos de materiais e fluxos
de energia. A percepção da profunda unidade da vida, diante da sua vasta
diversidade, é de uma complexidade sem paralelo em toda a ciência e também
demanda uma compreensão dos mecanismos de codificação genética, que são a um
só tempo uma estereoquímica e uma física da organização molecular da vida. Ter
uma noção de como operam esses níveis submicroscópicos da Biologia não é um
luxo acadêmico, mas sim um pressuposto para uma compreensão mínima dos
mecanismos de hereditariedade e mesmo da biotecnologia contemporânea, sem os
quais não se pode entender e emitir julgamento sobre testes de paternidade pela
análise do DNA, a clonagem de animais ou a forma como certos vírus produzem
imunodeficiências (BRASIL, 2000, p. 9-10).

Destarte, durante as aplicações dos planos de aula de Biologia os conteúdos de Genética, Evolução e Ecologia devem ser trabalhados de forma interdisciplinar. Além disso, as mediações devem ser aplicadas visando: "conhecer a estrutura molecular da vida, os mecanismos de perpetuação, diferenciação das espécies e diversificação intraespecífica, a importância da biodiversidade para a vida no planeta" (BRASIL, 2000, p. 14-15); "conhecer algumas explicações sobre a diversidade das espécies, seus pressupostos, seus limites, o contexto em que foram formuladas e em que foram substituídas ou complementadas e reformuladas" (BRASIL, 2000, p. 17); aprender "as relações entre alterações ambientais e modificações dos seres vivos, estas últimas decorrentes do acúmulo de alterações genéticas"; compreender "a variabilidade, como conseqüência de mutações e de combinações diversas de material genético"; perceber "a própria ação da natureza selecionando combinações genéticas que se expressam em características adaptativas"; compreender "a reprodução, que possibilita a permanência de determinado material genético na população" e realizar "a interpretação do processo de formação de novas espécies [...] numa população, em certas condições de isolamento geográfico e reprodutivo" (BRASIL, 2000, p. 18). 
Contudo, nos próprios PCNEM's há o reconhecimento do grau de complexidade desses conteúdos através das frases "a percepção da profunda unidade da vida, diante da sua vasta diversidade, é de uma complexidade sem paralelo em toda a ciência" (BRASIL, 2000, p. 9). Adiante é feita outra constatação do nível de ensino e aprendizado requerido seguida de uma orientação para superação desta realidade:

Para o aprendizado desses conceitos, bastante complicados, é conveniente criaremse situações em que os alunos sejam solicitados a relacionar mecanismos de alterações no material genético, seleção natural e adaptação, nas explicações sobre o surgimento das diferentes espécies de seres vivos [grifo nosso] (BRASIL, 2000, p.17).

No entanto, nas escolas do Ensino Médio público brasileiro esta realidade enfrenta problemas de superação. Segundo Cicillini (1993), os conteúdos de evolução biológica são colocados apenas como mais um tópico ao final do programa, apesar de estarem presentes nos livros didáticos e nas propostas curriculares de Biologia. Os principais fatores que estimulam a perpetuação desta dificuldade, segundo ela, são: "a baixa condição socioeconômica dos alunos, o estímulo ao consumo, a restrição de mercado de trabalho", pois "influenciam a concepção de escola e o currículo vivenciado" (p. 19). Além destes fatores, Cicillini (1993) e Almeida e Falcão (2010) consideram os temas polêmicos devido ao envolvimento de questões religiosas e filosóficas que dizem respeito ao surgimento e relacionamento da vida na Terra.

Por outro lado, a constatação da realidade precária em que se encontra o ensino brasileiro, em especial o de biologia, intensifica o desenvolvimento de novas metodologias e abordagens de ensino e de aprendizagem para minimizar tanto as dificuldades encontradas na elaboração e abordagem dessas temáticas por parte dos professores quanto na compreensão dos conceitos por parte dos alunos.

O cenário educacional atual está mais voltado à pesquisa em ensino e utilização de ferramentas não usuais, mais motivadoras, que proporcionem maiores e melhores subsídios para o processo de ensino-aprendizagem. Assim sendo, cabe ao professor analisar recursos pedagogicamente aplicáveis, adaptáveis, para envolver e provocar a curiosidade dos alunos que fazem parte da "geração digital”, motivando-os, visando à produção de conhecimento cada vez mais interessante, lúdica e autônoma.

Através de tecnologias associadas é possível potencializar o processo educacional. É possível encontrar alguns softwares que podem ser utilizados como apoio ao trabalho docente enriquecendo sua prática pedagógica, proporcionando momentos de motivação e interesse dos alunos e possibilitando representações de fenômenos do mundo real. 
Os Parâmetros Curriculares Nacionais demonstram também a importância do conhecimento biológico e das tecnologias a ele associadas, denotando que "apropriar-se desses códigos, dos conceitos e métodos relacionados a cada uma das ciências, compreender a relação entre ciência, tecnologia e sociedade, significa ampliar as possibilidades de compreensão e participação efetiva nesse mundo" (PCN, 2000, p.14).

Dentre as recentes inovações metodológicas para o Ensino, destacam-se os Objetos Virtuais de Aprendizagem (OVA). Segundo Spinelli (2007), em linhas gerais, um objeto virtual de aprendizagem representa qualquer recurso digital reutilizável que auxilia na aprendizagem de um determinado conceito e, concomitantemente, estimula o desenvolvimento de capacidades pessoais como a imaginação e a criatividade. Spinelli ainda desenvolve as potencialidades dos OVA's:

\footnotetext{
Dessa forma, um objeto virtual de aprendizagem pode tanto contemplar um único conceito quanto englobar todo o corpo de uma teoria. Pode ainda compor um percurso didático, envolvendo um conjunto de atividades, focalizando apenas determinado aspecto do conteúdo envolvido, ou formando, com exclusividade, a metodologia adotada para determinado trabalho (SPINELLI, 2007, p. 7).
}

Os Objetos Virtuais de Aprendizagem são exemplos de tecnologias associadas ao conhecimento biológico. Cada OVA oferece uma maneira de contribuir com o processo educacional, porém é preciso provocar a reflexão do seu uso para que se tornem instrumentos para inovação de práticas pedagógicas. Para uma boa experiência de utilização é necessário que o professor observe o público-alvo destinado; a forma de utilização; os materiais de suportes necessários para o uso do software; a forma de apresentação do conteúdo; o estímulo à criatividade, ao raciocínio, ao trabalho em grupo; e o nível de envolvimento do usuário porque o aluno aprende melhor quando lhe é proporcionado vocabulário adequado, ambiente familiar ao de seu cotidiano e liberdade para descobrir as relações existentes entre os conceitos aprendidos e a realidade vivida.

O Estágio é um processo que, por meio do contato com teorias e práticas pedagógicas, capacita o futuro professor, dentre outras habilidades, para a utilização de tecnologias associadas à Educação como os Objetos Virtuais de Aprendizagem. Obrigatório para o licenciando, o estágio se inicia, sob a tutela de um professor-orientador, com: a realização de visitas técnicas aos espaços educativos formais e não formais; a participação de professores convidados; o desenvolvimento de estágio na escola por meio da observação e da regência; e culmina com a elaboração e a execução de projetos educativos.

Durante a realização do "Estágio Supervisionado Obrigatório em Objeto Virtual de Aprendizagem" pela autora, propôs-se a elaboração de um site focado nas necessidades dos alunos do $3^{\circ}$ ano do Ensino Médio de uma escola pública periférica para ser utilizado com a turma em três regências, pois é essencial promover o acesso a diferentes tipos de metodologias e abordagens de ensino-aprendizagem em um contexto de vulnerabilidade social e econômica (CRUZ; HAETINGER, 2012) assim como é evidente a necessidade e os benefícios de uma educação centrada no discente (HAZOFF JUNIOR, 2008). Nessa 
perspectiva, são reunidas as maiores dificuldades que foram apontadas pelos alunos a respeito dos últimos conteúdos abordados pela professora supervisora (Genética, Evolução e Ecologia) para nortear a construção do site e, através dele, auxiliar a aprendizagem dos tópicos mencionados por meio de explicações teóricas, exemplos, imagens e um simulador. Assim, além de OVA, o site é um Repositório de Objetos Virtuais de Aprendizagem por conter dentro dele outro OVA em forma de simulador (ALMEIDA, 2010).

\section{0 processo de elaboração do site}

Para a elaboração do site foi necessário, primeiramente, identificar as dificuldades encontradas pelos alunos no processo de ensino-aprendizagem. Em uma atividade na escola, após ser apresentada a proposta de ensino aos alunos, foi solicitado aos mesmos que recordassem das maiores dificuldades com relação aos últimos conteúdos de Biologia abordados até àquele momento e/ou maiores dúvidas de Biologia para o Exame Nacional do Ensino Médio (ENEM). Sabendo-se do receio de julgamentos entre adolescentes, foi recomendado que não se identificassem e que os pedaços de papel entregues a cada aluno fossem dobrados e, posteriormente, colocados em uma pequena caixa (Fig. 1).

Figura 1 - Caixa de dúvidas.

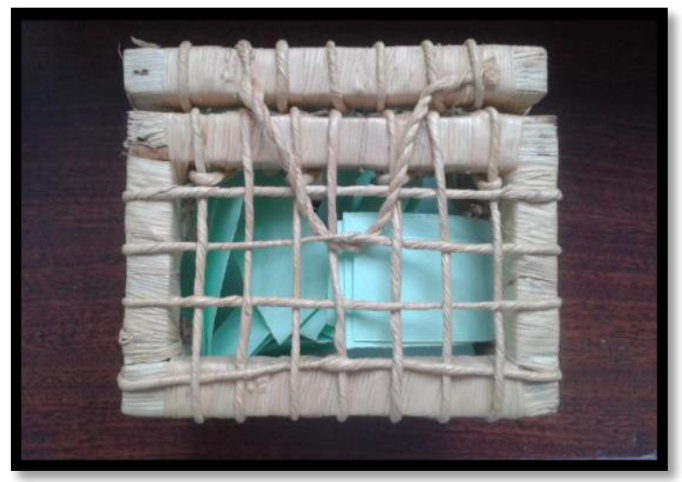

Fonte: Elaborado pela autora, 2018.

As dificuldades de aprendizagem foram identificadas, constatando-se a participação de 14 alunos. Para melhor desenvolvimento da metodologia de ensino e da abordagem, as dificuldades foram separadas em dois temas de acordo com o conteúdo, como mostra o Quadro 1: 
DOI: https://doi.org/10.46667/renbio.v13i1.265

Quadro 1 - Dificuldades destacadas pelos alunos, anonimamente.

\begin{tabular}{|c|c|}
\hline Tema & Dúvida \\
\hline Genética & $\begin{array}{l}\text { "Variabilidade genética e Seleção Natural". } \\
\text { "Mutação". } \\
\text { "O que é Seleção Natural?". } \\
\text { "As limitações da Seleção Natural". } \\
\text { "Sobre Seleção Natural, o que é o que ocorre? Não entendi sobre a Seleção } \\
\text { Natural". } \\
\text { "A resistência de bactérias aos antibióticos". }\end{array}$ \\
\hline Ecologia & $\begin{array}{l}\text { "Níveis tróficos? Biocenose?". } \\
\text { "Abiótico/Biótico, fatores bióticos". } \\
\text { "Não entendi a matéria de ecologia". } \\
\text { "Gostaria de entender mais sobre fatores abióticos e Seleção Natural". } \\
\text { "Tróficos (antepenúltima matéria). Eu faltei!". } \\
\text { "Ecossistemas". } \\
\text { "O que é relações ecológicas? (Para o ENEM)". } \\
\text { "O que é níveis de organização?". }\end{array}$ \\
\hline
\end{tabular}

Fonte: Elaborado pela autora, 2018.

Por meio da identificação das dúvidas foi possível também constatar os conteúdos com maior índice de dificuldade. Dentre quatorze dúvidas mencionadas, o conteúdo curricular "Seleção Natural" esteve presente cinco vezes e os conteúdos curriculares "Biocenose" e "Níveis tróficos" foram citados três vezes. No entanto, não foi possível distinguir qual dos dois temas, Genética ou Ecologia, apresentou maior grau de dificuldade, pois ambos foram recorrentes.

Com foco na melhora do processo de ensino-aprendizagem, atentando à Teoria da Inteligência Múltipla de Gardner (2008), buscou-se auxiliar as dúvidas utilizando diversas metodologias a fim de abranger as diversas formas de aprendizagem. Para englobar diferentes proficiências, além de desenvolver explicações orais, foi criada uma página de hipertexto (site) contendo textos explicativos (adaptados e objetivos) com exemplos de situações reais, representações gráficas coloridas para cada exemplo e ainda um objeto virtual simulador sobre a Seleção Natural.

Para seleção dos textos explicativos e exemplos contextualizados foram usados os livros didáticos Biologia Evolutiva (FUTUYMA, 2009), Introdução a Genética (GRIFFITHS et al., 2009) e A Economia da Natureza (RICKLEFS, 2010), presentes na biblioteca do campus universitário. O conteúdo textual que compõem site está descrito no Quadro 2: 
DOI: https://doi.org/10.46667/renbio.v13i1.265

Quadro 2 - Fenômenos, citados pelos alunos em suas dúvidas, com seus respectivos conceitos e exemplos baseados na literatura.

\begin{tabular}{|c|c|}
\hline Fenômeno & Conceito \\
\hline Genética & a ciência que estuda a transmissão das características hereditárias. \\
\hline $\begin{array}{l}\text { Seleção } \\
\text { Natural }\end{array}$ & $\begin{array}{l}\text { É um dos quatro mecanismos básicos da evolução. A seleção natural é } \\
\text { uma avaliação estatística da diferença na sobrevivência ou reprodução } \\
\text { entre entidades que divergem em uma ou mais características. Aplica-se a } \\
\text { toda a natureza e dentro das populações e pode ou não impor luta e } \\
\text { competição entre os indivíduos, selecionando o organismo mais apto a } \\
\text { viver em um determinado ambiente. } \\
\text { Esse mecanismo pode causar alterações na frequência gênica da } \\
\text { população e por isso é um mecanismo de mudanças evolutivas. } \\
\text { Ex. (1) Imagine que besouros verdes são mais fáceis para os pássaros } \\
\text { enxergaram e, portanto, comerem. (2) Besouros marrons são um pouco } \\
\text { mais prováveis de sobreviverem e procriarem. (3) Eles passam seus genes } \\
\text { para coloração marrom para seus descendentes. (4) Logo, na próxima } \\
\text { geração, besouros marrons serão mais comuns do que na geração anterior. }\end{array}$ \\
\hline $\begin{array}{c}\text { Seleção } \\
\text { direcional }\end{array}$ & $\begin{array}{l}\text { É aquela que seleciona indivíduos de um determinado fenótipo extremo. } \\
\text { Ex. A pesca intensa selecionou salmões maiores no noroeste do Pacífico. }\end{array}$ \\
\hline $\begin{array}{c}\text { Seleção } \\
\text { estabilizadora }\end{array}$ & $\begin{array}{l}\text { Os indivíduos de fenótipos intermediários são selecionados. } \\
\text { Ex. Em regiões da África a doença anemia falciforme que ocorre pela } \\
\text { presença do alelo "s" (ss ou Ss) ocorre em heterozigose "Ss", conferindo } \\
\text { proteção contra malária. }\end{array}$ \\
\hline $\begin{array}{c}\text { Seleção } \\
\text { disruptiva }\end{array}$ & $\begin{array}{l}\text { Os indivíduos com fenótipos extremos são selecionados. } \\
\text { Ex. Tentilhões africanos que são adaptados a comer sementes variam em } \\
\text { tamanho, mas as formas intermediárias são pouco observadas porque } \\
\text { existem sementes que variam em dureza. Os tentilhões maiores } \\
\text { conseguem alimentar-se de sementes duras, e os menores alimentam-se de } \\
\text { sementes macias. }\end{array}$ \\
\hline Mutação & $\begin{array}{l}\text { É um dos quatro mecanismos básicos da evolução. Mutação é qualquer } \\
\text { alteração passível de ser herdada (passar à descendência). Uma mutação } \\
\text { pode ser molecular, genômica ou cromossômica e ocorre aleatoriamente. } \\
\text { As mais comuns são adição, deleção, duplicação e inversão. }\end{array}$ \\
\hline $\begin{array}{l}\text { Variabilidade } \\
\text { Genética }\end{array}$ & $\begin{array}{l}\text { A variabilidade genética diz respeito às variações dos genes entre } \\
\text { indivíduos de uma população. } \\
\text { Ex. Alguns indivíduos de uma população de besouros marrons podem ter } \\
\text { se juntado a uma população de besouros verdes. Isso faria com que a } \\
\text { frequência de genes para besouros marrons ficasse frequente na } \\
\text { população de besouros verdes, aumentando a variabilidade genética }\end{array}$ \\
\hline
\end{tabular}

REnBio - Revista de Ensino de Biologia da SBEnBio - ISSN: 1982-1867 - vol. 13, n. 1, p. 3-21, 2020 
DOI: https://doi.org/10.46667/renbio.v13i1.265

\begin{tabular}{|c|l|}
\hline & daquela população. \\
\hline Ecologia & $\begin{array}{l}\text { É a ciência que estuda as relações dos seres vivos entre si ou com o meio } \\
\text { onde vivem. }\end{array}$ \\
\hline Ecossistema & $\begin{array}{l}\text { Consiste em um sistema que inclui os seres vivos, o ambiente, suas } \\
\text { características físico-químicas e as relações entre os seres vivos e entre os } \\
\text { seres vivos e o ambiente. }\end{array}$ \\
\hline
\end{tabular}

Fonte: Elaborado pela autora, 2018.

Tais exemplos textuais possuem correspondência visual com elementos gráficos igualmente fundamentados nos livros didáticos referenciados anteriormente. Para os exemplos dos conteúdos curriculares de "Deriva Genética" e "Mutação" e para o exemplo introdutório do conceito de "Seleção Natural" foram utilizadas representações gráficas do Instituto de Biologia da Universidade de São Paulo (IB-USP) (Fig. 2, 3 e 4):

Figura 2 - Representação da mutação em uma colônia de bactérias.

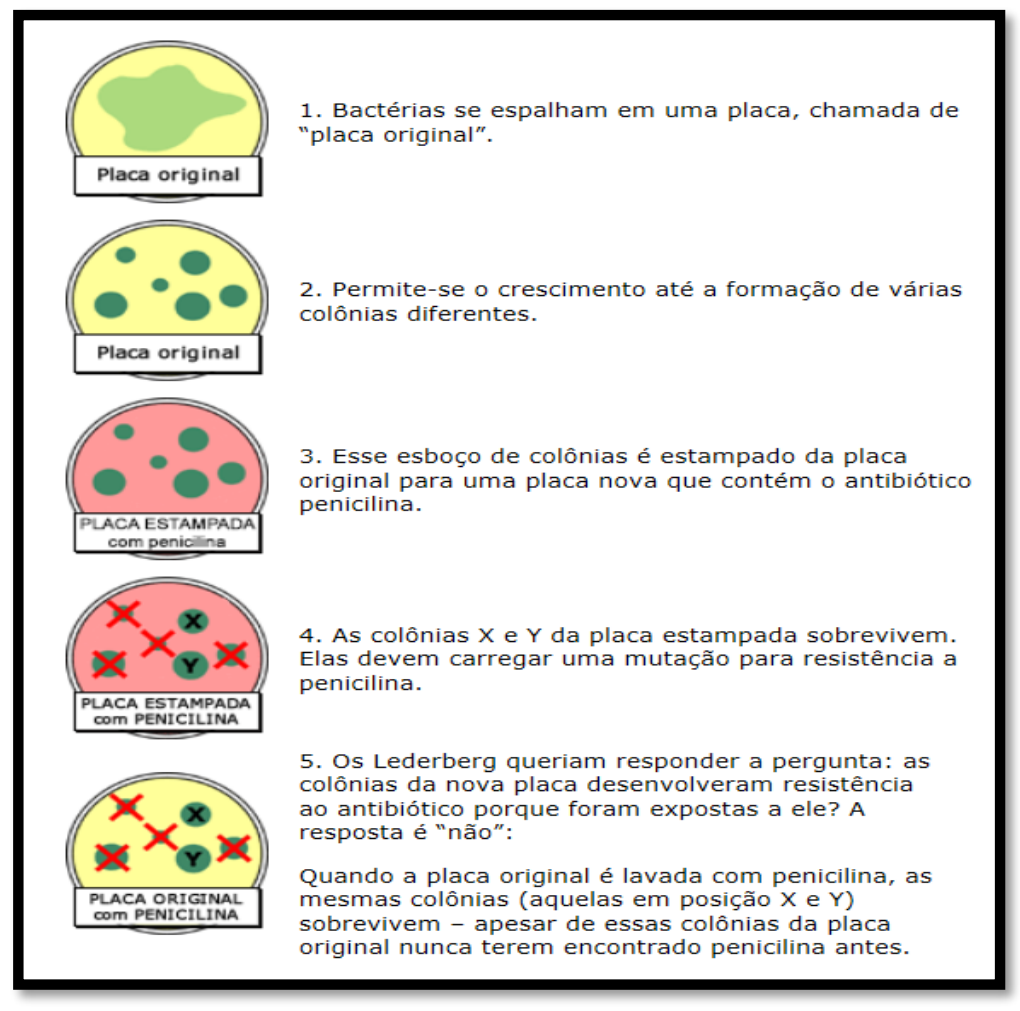

Fonte: IB-USP, 2018. 
Figura 3 - Representação da ação da Deriva Genética em uma população de besouros.

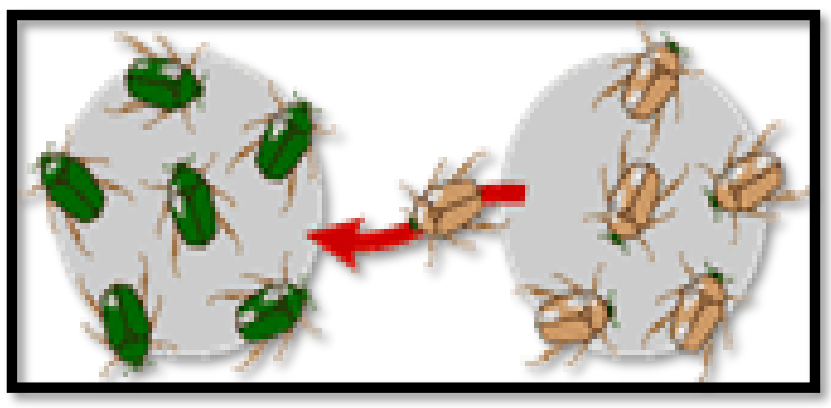

Fonte: IB-USP, 2018.

Figura 4 - Representação da ação da Seleção Natural em uma população de besouros.

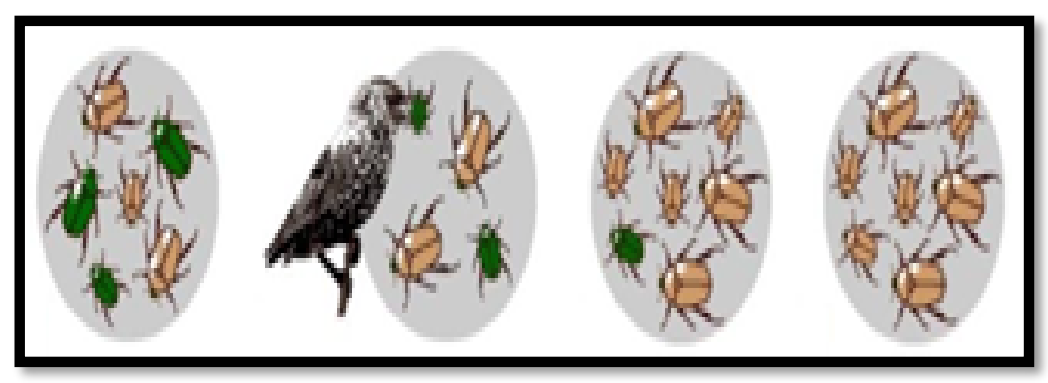

Fonte: IB-USP, 2018.

A explanação visual das possíveis formas de ocorrência da Seleção Natural foi feita utilizando-se a ferramenta Paint 3D, da Microsoft. As imagens elaboradas para auxiliar a compreensão dos tipos de Seleção Natural estão representadas pelas figuras 5, 6 e 7:

Figura 5 - Representação gráfica da seleção direcional que ocorreu com os salmões no Oeste do Pacífico.

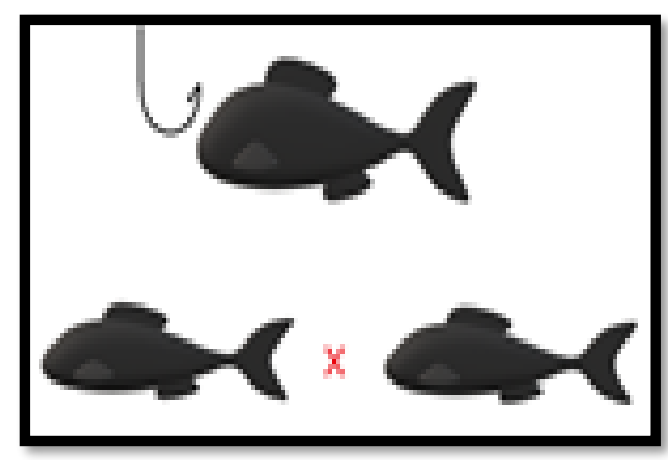

Fonte: Elaborado pela autora, 2018. 
Figura 6 - Representação gráfica da seleção estabilizadora que ocorreu em regiões da África em decorrência da Malária.

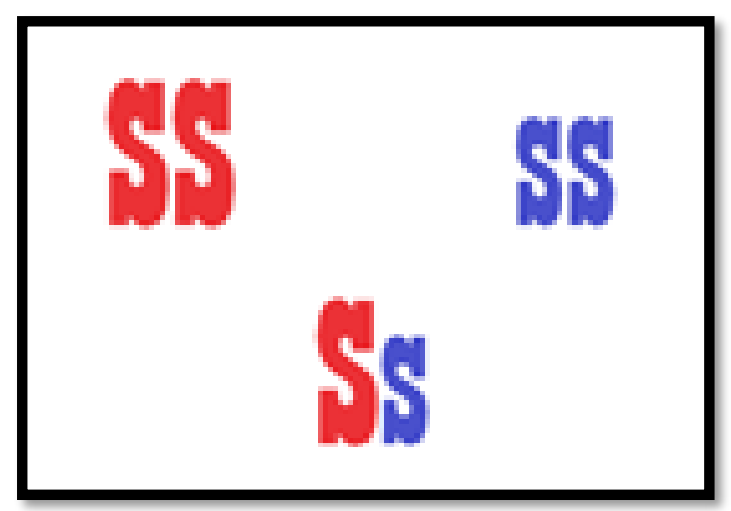

Fonte: Elaborado pela autora 2018.

Figura 7 - Representação gráfica da seleção disruptiva que ocorreu com os tentilhões africanos.

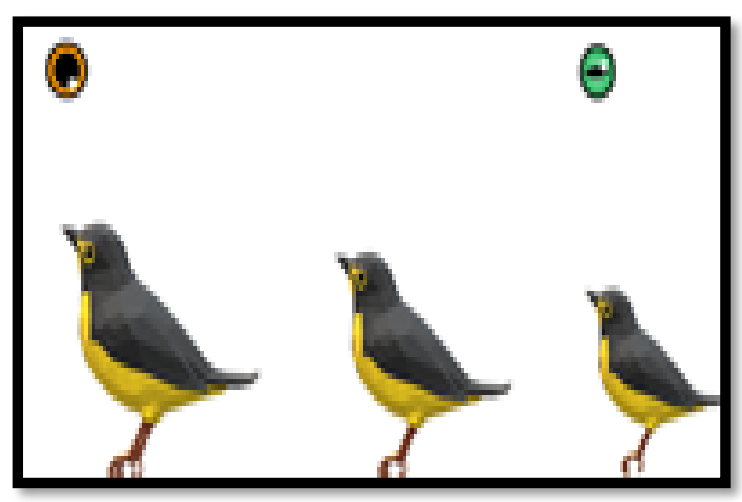

Fonte: Elaborado pela autora, 2018.

Os conteúdos considerados como difíceis que constituem o tema Ecologia foram agrupados em um único esquema para que houvesse integração dos conceitos, reconhecimento dos níveis hierárquicos existentes, construção de uma sequência lógica e, principalmente, para que o aluno se situasse no esquema ao ouvir e/ou ler a explicação. Assim, foi elaborado também através do Paint $3 D$ um fluxograma sobre Ecossistemas (Fig. 8): 
Figura 8 - Representação esquemática dos conceitos de Ecologia

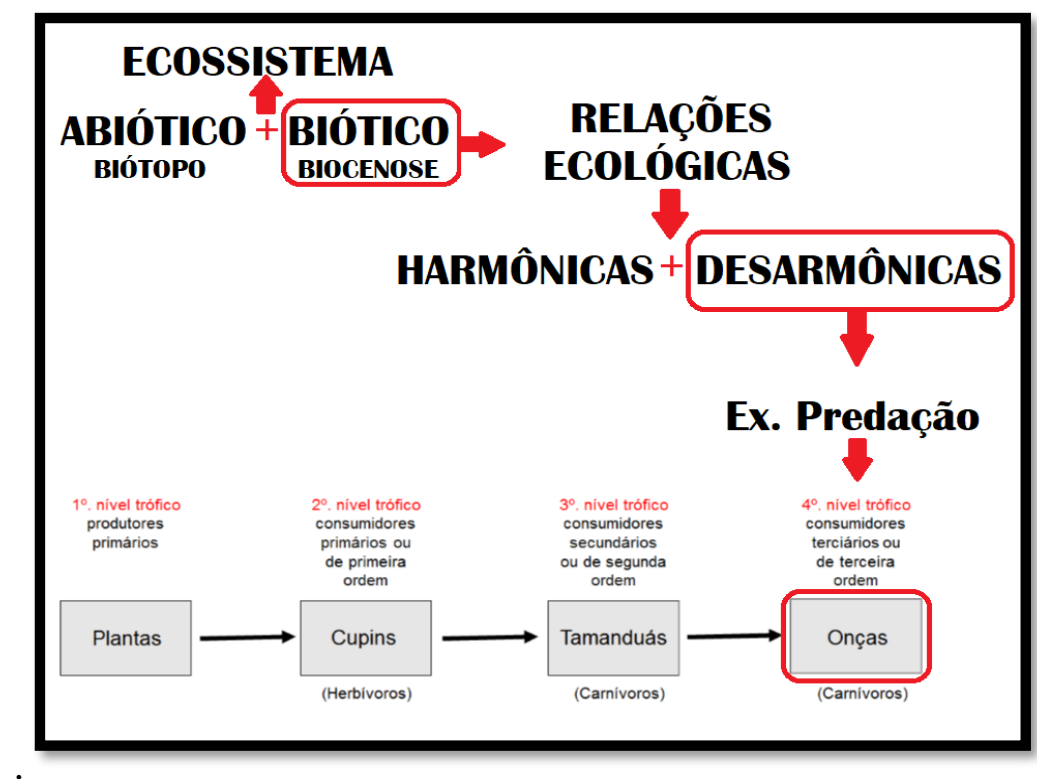

Fonte: Elaborado pela autora, 2018.

O Objeto Virtual de Aprendizagem selecionado para inovar a forma de abordagem e reforçar o conteúdo ministrado sobre a Seleção Natural foi o simulador, presente no repositório virtual RIVED, "Selecionando Moscas"2, cujos objetivos são: organizar resultados experimentais sobre teoria evolutiva, analisar resultados experimentais e explicar os resultados obtidos utilizando o conceito de Seleção Natural em moscas presentes em seis ambientes diferentes (Fig. 9).

Figura 9 - Simulador "Selecionando Moscas".

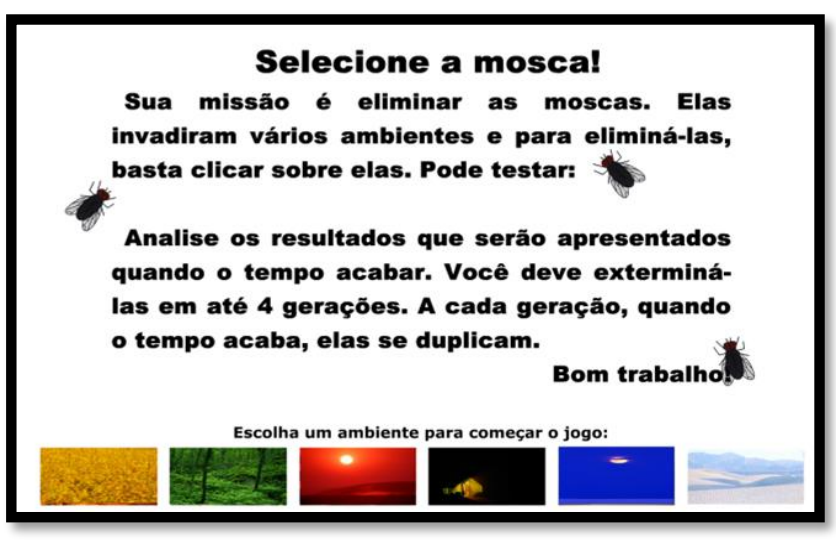

Fonte: RIVED, 2018.

Após a criação do conteúdo se iniciou a construção da estrutura do site, em si. O campo de estágio escolhido pela autora foi uma escola pública periférica e devido às escolas públicas utilizarem o Sistema Operacional (SO) Linux em seus computadores e esta escola

2 Disponível no repositório www.rived.mec.gov.br/. Acesso em outubro de 2018

REnBio - Revista de Ensino de Biologia da SBEnBio - ISSN: 1982-1867 - vol. 13, n. 1, p. 3-21, 2020 
DOI: https://doi.org/10.46667/renbio.v13i1.265

não possuir conexão com a Internet, a elaboração da estrutura do site teve de ser realizada no software BlueGriffon, um editor de páginas da web gratuito que opera no SO em questão, para que a página em hipertexto criada pudesse ser visualizada no navegador a partir do software (off-line).

Ao final do desenvolvimento do site foi lhe dado o título "BioDúvidas"3 e o subtítulo "Auxiliando dúvidas sobre Biologia através de diferentes metodologias de ensino" para reforço do seu propósito. Precedendo a exposição do conteúdo curricular, fez-se a explicação dos conceitos de OVA. A estrutura e o conteúdo do site são bem simples, claros, objetivos e possuem destaques na cor vermelha, em itálico e negrito para as informações mais importantes do texto, visando facilitar a compreensão do conteúdo como foi pontuado por Mayer (2005) em seus critérios para elaboração de OVA's (Fig. 10).

Figura 10 - Site Biodúvidas finalizado.

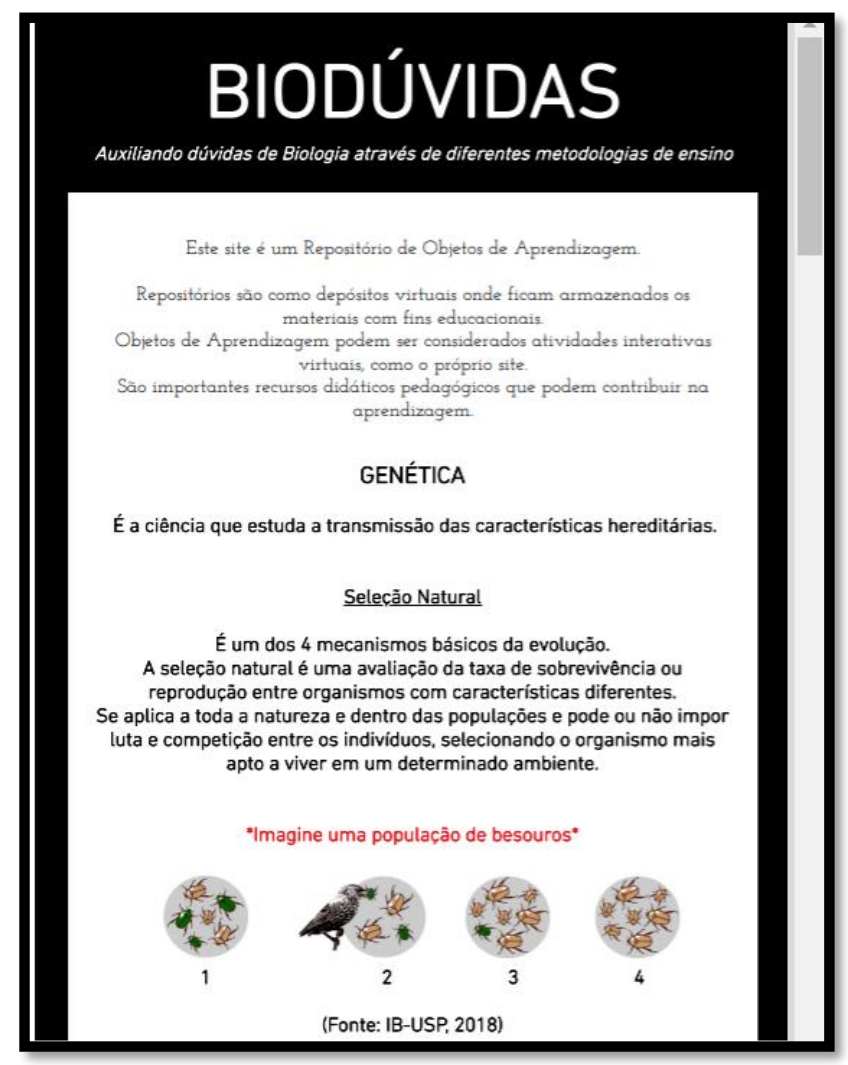

Fonte: Elaborado pela autora, 2018.

\footnotetext{
${ }^{3}$ A versão off-line do site Biodúvidas, aplicada no campo de estágio, está disponível online em https://bioduvidas.wixsite.com/bioduvidas. Acesso em fevereiro de 2020.

REnBio - Revista de Ensino de Biologia da SBEnBio - ISSN: 1982-1867 - vol. 13, n. 1, p. 3-21, 2020
} 


\section{$3 \mathrm{O}$ desenvolvimento da avaliação do site e do simulador}

Há necessidade de coerência no desenvolvimento de Objetos Virtuais de Aprendizagem tanto pelo caráter pedagógico quanto pelo caráter técnico para que os objetivos determinados possam ser alcançados satisfatoriamente. A constatação do nível de coerência existente nos aspectos técnicos e pedagógicos se dá através de um processo avaliativo.

A avaliação da aprendizagem proposta para o OVA simulador "Selecionando Moscas" foi pensada em duas etapas a serem aplicadas durante o percurso da aula: na primeira etapa avalia-se o entendimento do conceito de Seleção Natural em moscas, que foi explicado utilizando o simulador, e na segunda etapa avalia-se a compreensão e a retenção das explicações sobre os tipos de Seleção Natural, anteriores ao simulador. O processo avaliativo do ensino desenvolvido para o OVA site foi um questionário composto por quatro questões dissertativas dispostas a seguir no Quadro 3:

Quadro 3 - Questionário dissertativo avaliativo sobre o site.

\begin{tabular}{|l|}
\hline \multicolumn{1}{|c|}{ Avaliação do site } \\
\hline 1. Você considera que suas dúvidas foram resolvidas? Quais? \\
\hline 2. Você teve alguma dificuldade para usar o Objeto Virtual? \\
\hline 3. O que você considera importante ter nas explicações? \\
\hline 4. Dê uma nota de 0 a 10. \\
\hline
\end{tabular}

Fonte: Elaborado pela autora, 2018.

\section{0 contexto de aplicação}

O campo de estágio escolhido pela autora foi uma escola pública periférica. Segundo a Agência Brasil (TORKANIA, 2016), apenas 4,5\% das escolas públicas do país têm todos os itens de infraestrutura previstos em lei, no Plano Nacional de Educação (PNE). No Ensino Fundamental, 4,8\% das escolas possuem todos os itens e no Ensino Médio, a porcentagem sobe para $22,6 \%$, mas, as condições de infraestrutura ainda continuam desfavoráveis para o ensino tecnológico (TORKANIA, 2016).

A escola em questão, como exceção, possuía um laboratório de informática com um projetor e computadores, mas não para todos os alunos da turma e alguns dos computadores não estavam funcionando. Além disso, os computadores não possuíam conexão com a Internet - tornando necessário que os arquivos dos OVA's, site e simulador, fossem transferidos para cada um dos computadores que estavam funcionando através do uso de um pendrive. 
DOI: https://doi.org/10.46667/renbio.v13i1.265

Esta turma do $3^{\circ}$ ano do Ensino Médio possuía uma única aula de Biologia por dia em dois dias da semana, sendo necessárias três horas/aulas para a aplicação da proposta. Para a primeira hora/aula de aplicação do produto - site com o simulador - foi reservado, com antecedência, o laboratório de informática da escola.

No entanto, no dia reservado um temporal acometeu a manhã do bairro em que a escola residia, causando imprevistos aos professores do Ensino Fundamental que lecionavam para os alunos remanescentes da escola municipal daquele conjunto habitacional, impedindoos de comparecerem. Devido à ausência de seus professores os alunos do E. F. ficaram impossibilitados de irem para o ginásio como pretendido, situado em outro quarteirão. Os imprevistos recaíram sobre o laboratório de informática reservado, de modo que o projetor foi destinado para que os alunos do E.F. pudessem assistir a filmes.

Assim, a exposição do site teve de ser realizada de forma improvisada, por meio de prints (fotos) feitos por precaução, no notebook da professora supervisora. Portanto, não foi possível realizar a aplicação do simulador "Selecionando Moscas" neste dia.

A inauguração desta primeira aula foi feita com a recordação dos propósitos do site para a turma e para os alunos que faltaram no dia da coleta de dúvidas. Devido ao pequeno espaço de visualização foi pedido à turma que se aproximasse da mesa que continha o notebook para, principalmente, visualizar as representações gráficas dos exemplos, e para maior participação na aula. Em seguida foram explanados todos os conceitos e exemplos de Genética e Ecologia, respectivamente. Foi percebida a captura da atenção e a participação de boa parte da turma durante a aula.

Destacou-se um momento: Durante a explicação da Seleção Natural direcional em salmões (Fig. 5), os alunos aparentavam a necessidade de se explicitar que os salmões não selecionados são adultos de tamanho pequeno, e não filhotes. Descobriu-se que era exatamente o que estavam imaginando. Após esta percepção, foi explicitado que, semelhantemente, na representação da Seleção Natural disruptiva os tentilhões pequenos são adultos.

$\mathrm{Na}$ segunda aula, o laboratório, previamente reservado, foi acessado com antecedência para a instalação do programa BlueGriffon e da cópia do arquivo hmtl para acesso ao site em cada um dos computadores que estavam funcionando na escola, com o uso de um pendrive. Apesar de inúmeras tentativas de inserção da senha cedida pela instituição para instalações, os computadores não permitiram que a instalação fosse concluída e, portanto, a execução do simulador seria feita usando o notebook da estagiária.

Infelizmente, houve outro imprevisto. A aula teve duração de apenas 20 minutos devido à ocorrência do "Trote do Terceirão", um momento de descontração para os alunos do $3^{\circ}$ ano que a própria professora supervisora não previu.

Inicialmente, foram retomados os conceitos sobre Seleção Natural ministrados na aula anterior, utilizando-se o projetor da sala de informática. Após a retomada dos conceitos, o OVA foi apresentado, explicando-se objetivos, finalidades e o seu funcionamento.

REnBio - Revista de Ensino de Biologia da SBEnBio - ISSN: 1982-1867 - vol. 13, n. 1, p. 3-21, 2020 
DOI: https://doi.org/10.46667/renbio.v13i1.265

Dispondo-se o notebook no centro da sala, os alunos foram convidados a jogarem no simulador com a orientação de que deveriam selecionar o maior número possível de moscas mais adaptadas (pretas, verdes e brancas) em três ambientes diferentes (preto, verde e branco) (Fig. 11).

Figura 11 - Aplicação do OVA “Selecionando Moscas” em um notebook.

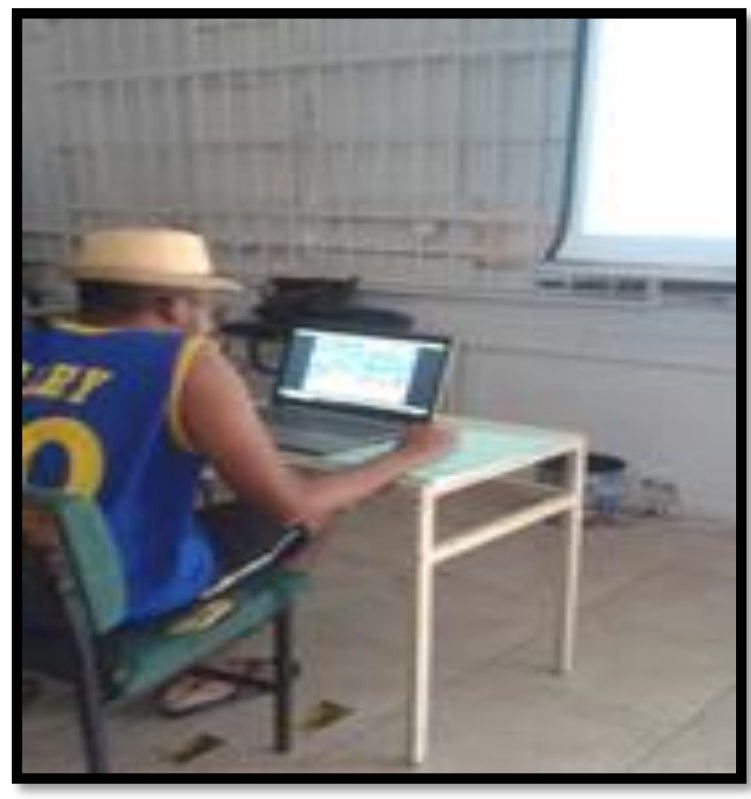

Fonte: Elaborado pela autora, 2018.

No início da aplicação os alunos ficaram receosos quanto à participação por vergonha, em especial as mulheres que necessitaram de um maior incentivo - apenas duas alunas participaram, totalizando três jogadas femininas. Após compreenderem o jogo, os estudantes se aglomeraram ao redor dos jogadores, alguns se levantavam, faziam torcida, outros queriam repetir várias vezes, todos riram e muitos apostaram, destacando-se um deles: "Se você eliminar mais moscas do que eu, te pago uma Coca-Cola!'”. Todos os alunos concordavam que era difícil selecionar as moscas que estavam em seus ambientes ideais.

Após 20 rodadas ( 9 no ambiente preto, 7 no ambiente verde e 4 no ambiente branco), avaliou-se o processo de ensino-aprendizagem. Primeiramente, foi explicado que para esta aula foi solicitado o contrário: que eliminassem as moscas aptas a um determinado ambiente para comprovar a teoria de que o mais adaptado ao meio possui maior chance de sobrevivência. Para verificar se estavam compreendendo os conceitos, foram feitos os seguintes questionamentos: "Qual mosca está mais adaptada, têm mais chances de sobreviver e se reproduzir no ambiente preto? No ambiente branco? E no ambiente verde?". Então, os alunos responderam: a mosca preta, a mosca branca e a mosca verde, respectivamente.

Em seguida, foram avaliadas a compreensão e a apropriação das explicações que abordaram os tipos de Seleção Natural anteriormente por texto, voz, imagem e OVA.

REnBio - Revista de Ensino de Biologia da SBEnBio - ISSN: 1982-1867 - vol. 13, n. 1, p. 3-21, 2020 
DOI: https://doi.org/10.46667/renbio.v13i1.265

Empregou-se a questão: "Qual é, então, o tipo de Seleção Natural representado na simulação? Levantem as mãos os alunos que, com base nas explicações, apontam ser a direcional; a estabilizadora; ou a disruptiva". A maioria das respostas se concentrou entre as duas últimas opções. Assim sendo finalizando a aula, foi feita a resolução da questão por meio da retomada do exemplo de Seleção Natural em uma população de besouros (Fig. 4).

Em reunião com a professora supervisora foi feita outra avaliação da aprendizagem dos conteúdos de Ecologia, com base no desempenho da prova formulada pela professora. Segundo a docente, os alunos, em média, se saíram bem na avaliação, que valia quatro pontos (Fig. 12). De acordo com a professora, a maioria dos erros correspondia às questões 03 e 04.

Figura 12 - Atividade avaliativa de Ecologia.

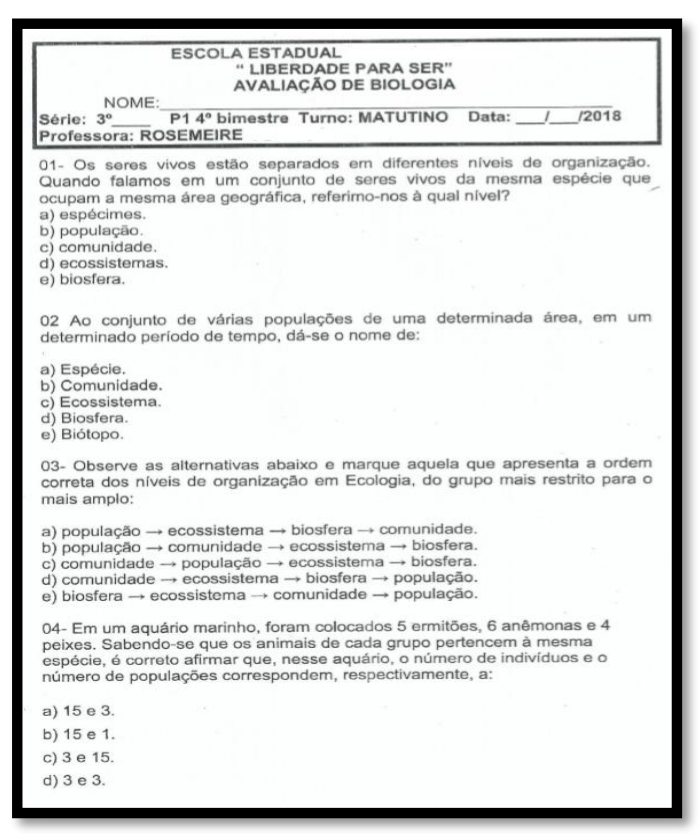

Fonte: Professora supervisora, 2018.

No terceiro dia de regência, deu-se continuação ao processo avaliativo sendo realizada a análise do processo de ensino-aprendizagem por parte dos alunos. Assim, foram distribuídas folhas de papel sulfite para que os alunos respondessem anonimamente, em forma de um parágrafo, às perguntas elaboradas no questionário (Quadro 3). No início, os poucos alunos presentes resistiram e, por isso, elucidou-se que a participação de todos era importante, não havendo resposta certa ou errada, para que o Ensino de Biologia e o desenvolvimento de OVA's evoluíssem, resultando na avaliação de quatro alunos (Quadro 4). 
DOI: https://doi.org/10.46667/renbio.v13i1.265

Quadro 4 - Avaliação dos alunos sobre o processo de ensino e aprendizagem.

\begin{tabular}{|c|}
\hline Avaliações \\
\hline $\begin{array}{l}\text { "Minha dúvida foi sobre Seleção Natural, eu aprendi que o ser vivo que se encaixa mais ao } \\
\text { ambiente tem mais chance de sobreviver. Por exemplo, se o ambiente é verde e o ser vivo é } \\
\text { verde ele tem mais chance de sobreviver. Nota 8,0”. Fonte: E.V.S. }\end{array}$ \\
\hline $\begin{array}{l}\text { "Sim, tirei a minha dúvida e a aula foi divertida e diferente. Mas, não entendi muito sobre a } \\
\text { mutação. Nota 6,0". Fonte: W.E D.S. }\end{array}$ \\
\hline $\begin{array}{l}\text { "As dúvidas foram sanadas em uma aula muito produtiva. O site é bem explicativo e fácil de } \\
\text { se entender. Nota } 10 \text { ". Fonte: J.F. }\end{array}$ \\
\hline $\begin{array}{l}\text { "A minha pergunta foi respondida claramente e eu consegui realizar a prova perfeitamente. } \\
\text { Para mim tudo ficou bem esclarecido. A nota é 9,0, pois faltaram risadas hehe". Fonte: } \\
\text { N.L.M. }\end{array}$ \\
\hline
\end{tabular}

Fonte: Elaborado pela autora, 2018.

Observando as avaliações dos alunos pode-se inferir que além das explicações orais a utilização do OVA site contendo explicações teóricas, exemplos, imagens e o simulador, auxiliou as dificuldades da turma e, por isso, a experiência de ensino-aprendizagem recebeu a pontuação média de 8,25. Com base nas avaliações, entende-se que não foram constatadas dificuldades para a utilização dos Objetos Virtuais e que a experiência de ensino e de aprendizagem proporcionada foi "diferente", "divertida" e "produtiva".

Entretanto, foi evidenciado na avaliação que o auxilio proposto deixou a desejar em relação conteúdo Mutação, mas não foram destacados os pontos que o discente considera importantes para a o ensino e a aprendizagem que estiveram presentes na resolução de sua dúvida (não revelada) e estiveram ausentes para a compreensão deste conteúdo. Refletindo-se sobre este ponto, foi reconhecida pouca atenção dada a esse conteúdo curricular quando comparado aos demais conteúdos do tema Genética, justificando-a como critério para a nota 6,0 recebida.

\section{Considerações finais}

Foi possível depreender, com base nos resultados e discussões obtidas, que a utilização de metodologias de ensino não usuais como Objetos de Aprendizagem Virtuais, quando preocupadas e orientadas pelas necessidades de seus alunos, desencadeia maior interesse que é refletido na maior participação e esta, por sua vez, gera melhor e maior aprendizado dos conteúdos curriculares. Também foi notável o desenvolvimento de habilidades cognitivas extremamente necessárias para se viver em um mundo digitalizado como o momento atual além de desenvolver competências fundamentais para a cidadania, como a avaliação de serviços e o trabalho em grupo, demonstrado no apoio e nas brincadeiras positivas com o colega no simulador. 
Essas ações evidenciaram que a elaboração de atividades centradas no aluno potencializa o desenvolvimento das dimensões conceitual, na compreensão dos processos e conceitos de Seleção Natural, procedimental, na execução da seleção de moscas através da simulação, e atitudinal, na formação crítica-reflexiva ao possibilitar a percepção da importância de sua participação no processo de ensino-aprendizagem e na compreensão da dimensão das relações entre os seres vivos.

Portanto, a precarização do Ensino e as dificuldades relatadas por professores e alunos não precisam ser mais um obstáculo para a defasagem do ensino de Biologia, em especial Genética e Evolução, nas escolas públicas brasileiras. Diante da constatação da realidade precária em que se encontram os espaços escolares - neste campo de estágio, exemplificada pela ausência de professores, computadores para todos os alunos, acesso à Internet e pela presença de buracos no chão das salas, cadeiras quebradas, não funcionamento de computadores e má realocação de alunos remanescentes - e, consequentemente, as dificuldades de abordagens diversificadas voltadas para o ensino de biologia deve-se tomar atitudes de luta por meio de movimentos e cobranças aos órgãos competentes e atitudes de resistência por meio da intensificação do desenvolvimento de novas metodologias e enfoques para minimizar tanto as dificuldades encontradas no planejamento e execução dessas temáticas por parte dos professores quanto na compreensão dos conceitos por parte dos alunos, realizando sempre sua parte na melhoria da educação pública brasileira.

\section{Referências}

ALMEIDA, Rosiney Rocha. Elaboração de um catálogo de objetos de aprendizagem digitais para o ensino do sistema digestório com ênfase no seu potencial como ferramenta de ensino e aprendizagem. 2010. 85f. Dissertação (Mestrado em Ensino de Ciências e Matemática) - Pontifícia Universidade Católica de Minas Gerais, Belo Horizonte, MG, 2010.

ALMEIDA, Argus Vasconcelos de; FALCÃO, Jorge Tarcísio da Rocha. As teorias de Lamarck e Darwin nos livros didáticos de biologia no Brasil. Ciência \& Educação, Bauru, v. 16, n. 3, 2010.

BRASIL, Ministério da Educação e do Desporto, Secretaria de Educação Fundamental. Parâmetros curriculares nacionais. Brasília: MEC/SEF, 1997.

BRASIL, Ministério da Educação e do Desporto, Secretaria de Educação Fundamental. Parâmetros curriculares nacionais: ensino médio. ciências da natureza, matemática e suas tecnologias. Brasília: MEC/SEF, 2000.

CICILLINI, Graça Aparecida. A evolução enquanto um componente metodológico para o ensino de biologia no $2^{\circ}$ grau. Educação e Filosofia, v. 7, n. 14, p. 17-37, 1993.

CRUZ, Marcia Elena Jochims Kniphoff da; HAETINGER, Werner. Inclusão Digital como possibilidade cultural, social e emancipatória. Revista Espaço Acadêmico, v. 12, n. 139, p. 41-47, 2012. 
FUTUYMA, Douglas J. Biologia evolutiva. 3. ed. Ribeirão Preto: FUNPEC, 2009.

GARDNER, Howard. A multiplicity of intelligences. In: MARIËN, Peter; ABUTALEBI, Jubin. Neuropsychological research: a review. New York: Psychology, 2008. p. 26-32.

GRIFFITHS, A. J. F., et al. Introdução à genética. 9. ed. Rio de Janeiro: Guanabara Koogan, 2009.

HAZOFF JÚNIOR, Waldemar; SAUAIA, Antonio Carlos Aidar. Aprendizagem centrada no participante ou no professor? Um estudo comparativo em Administração de Materiais.

Revista de Administração Contemporânea, v. 12, n. 3, p. 631-658, 2008.

INSTITUTO DE BIOCIÊNCIAS DA UNIVERSIDADE DE SÃO PAULO. Representação da ação da deriva genética em uma população de besouros. Disponível em: http://www.ib.usp.br/evosite/evo101/IIIC4Geneflow.shtml . Acesso em: 29 de outubro de 2018.

INSTITUTO DE BIOCIÊNCIAS DA UNIVERSIDADE DE SÃO PAULO. Representação da mutação em uma colônia de bactérias. Disponível em:

http://ecologia.ib.usp.br/evosite/evo101/IIIC1bLederberg.shtml Acesso em: 29 de outubro de 2018.

INSTITUTO DE BIOCIÊNCIAS DA UNIVERSIDADE DE SÃO PAULO. Representação da ação da Seleção Natural em uma população de besouros. Disponível em: http://www.ib.usp.br/evosite/evo101/IIIENaturalSelection.shtml Acesso em: 29 de outubro de 2018.

MAYER, Richard E. Cognitive theory of multimedia learning. The Cambridge Handbook of Multimedia Learning, v. 43, 2005.

RICKLEFS, R.E. A economia da natureza. 6 ed. Rio de Janeiro: Guanabara Koogan, 2010.

SPINELLI, Walter. Aprendizagem matemática em contextos significativos: objetos virtuais de aprendizagem e percursos temáticos. 2007. Dissertação (Mestrado em Educação) Faculdade de Educação, Universidade de São Paulo, São Paulo, SP, 2007.

TORKINIA, Mariana. Apenas 4,5\% das escolas têm infraestrutura completa prevista em lei, diz estudo. 26 jun. Agência Brasil. 2016. Disponível em:

http://agenciabrasil.ebc.com.br/educacao/noticia/2016-06/apenas-45-das-escolas-teminfraestrutura-completa-prevista-em-lei-diz . Acesso em: 30 de outubro de 2018. 